\title{
FREKUENSI ALAMI DAN MODE SHAPE BALOK EULER-BERNOULLI DAN BALOK TIMOSHENKO DENGAN METODE ELEMEN HINGGA
}

\author{
Filemon Arman ${ }^{1}$ dan Leo S. Tedianto ${ }^{2}$ \\ ${ }^{1}$ Program Studi Sarjana Teknik Sipil, Universitas Tarumanagara, Jl. Letjen S. Parman No.1 Jakarta \\ Email: filemonarman@ymail.com \\ ${ }^{2}$ Program Studi Sarjana Teknik Sipil, Universitas Tarumanagara, Jl. Letjen S. Parman No.1 Jakarta \\ Email: leotedi@gmail.com
}

\begin{abstract}
ABSTRAK
Balok merupakan elemen struktur yang sering digunakan di berbagai konstruksi. Biasanya struktur balok dianalisis dengan Teori Balok Euler-Bernoulli karena paling sederhana. Namun, untuk balok tinggi, analisis dengan teori ini menjadi kurang akurat karena tidak memperhitungkan deformasi geser. SNI memberi syarat L/h (rasio panjang bentang terhadap tinggi penampang balok) yang kurang dari 4 untuk dianalisis dengan lebih akurat. Balok tinggi lebih cocok dianalisis dengan Teori Balok Timoshenko karena teori ini memperhitungkan deformasi geser. Studi ini bertujuan untuk mengetahui seberapa besar perbedaan perilaku dinamik frekuensi alami dan mode shape antara Teori Balok Timoshenko dengan Teori Balok Euler-Bernoulli. Analisis dengan Teori Balok Euler-Bernoulli mengeluarkan hasil yang tidak sesuai dengan Teori Balok Timoshenko jika rasio L/h balok terlalu kecil. Hasil analisis teoritis ini juga dibandigkan dengan hasil dari program berbasis elemen hingga. Analisis dengan program berbasis elemen hingga mengeluarkan hasil yang sesuai dengan Teori Balok Timoshenko. Dengan adanya program analisis struktur pada komputer, struktur dapat dianalisis menggunakan metode elemen hingga dengan waktu yang lebih cepat.
\end{abstract}

Kata kunci: Teori Balok Euler-Bernoulli, balok tinggi, Teori Balok Timoshenko, frekuensi alami, mode shape.

\section{PENDAHULUAN}

Balok merupakan salah-satu komponen struktur yang sering digunakan dalam berbagai konstruksi. Dengan adanya balok, tegangan atau gaya dalam momen dan geser yang diterima pelat menjadi lebih kecil, sehingga tebal pelat yang dibutuhkan untuk menahan gaya dalam tersebut menjadi lebih tipis dan membuat berat total bangunan menjadi lebih ringan. Sebagian besar beban yang diterima oleh balok bekerja tegak lurus di sepanjang balok tersebut, sehingga gaya dalam momen dan lintang balok cukup besar. Gaya-gaya dalam tersebut diperoleh dari analisis struktur. Ada beberapa asumsi yang dibuat untuk mempermudah perhitungan. Asumsi-asumsi dari Teori Balok Euler-Bernoulli paling sering digunakan dalam perhitungan karena lebih sederhana dibanding teori yang lain. Asumsi-asumsi Teori Balok Euler-Bernoulli adalah sebagai berikut:

1. Penampang suatu balok adalah bidang yang kaku, sehingga bentuk dan ukuran penampang balok tersebut akan tetap sama walaupun posisinya berubah akibat diberikan beban.

2. Penampang suatu balok akan tetap datar setelah berdeformasi.

3. Penampang suatu balok akan tetap tegak lurus terhadap sumbu titik berat balok tersebut setelah berdeformasi.

Asumsi ketiga membuat teori ini tidak memperhitungkan deformasi geser. Teori Balok Timoshenko adalah teori balok yang tidak mengabaikan deformasi geser tersebut. Walaupun deformasi geser cenderung jauh lebih kecil dibanding deformasi lentur, untuk beberapa kasus balok yang memiliki rasio panjang balok dibandingkan dengan tinggi penampang yang kecil membuat deformasi geser menghasilkan dampak yang perlu diperhatikan (Li, 2013). Dengan begitu, analisis dengan Teori Balok Timoshenko akan menghasilkan analisis yang lebih akurat meskipun lebih sulit dilakukan. Analisis struktur perlu dilakukan untuk memastikan kekuatan bangunan mampu menahan beban-beban yang akan terjadi selama umur bangunan. Analisis statis biasa dapat digunakan untuk menganalisis struktur. Namun, jika beban yang perlu ditahan adalah beban dinamik, maka perlu dilakukan analisis dinamik. Beban dinamik adalah beban yang merupakan fungsi dari waktu seperti gempa, getaran mesin, atau ledakan. Frekuensi alami dan mode shape adalah perilaku dinamik yang penting karena bisa memberikan gambaran, getaran seperti apa yang akan terjadi pada suatu struktur jika tidak diredam dan tidak dipengaruhi gaya luar. 
Analisis dinamik menggunakan Teori Balok Timoshenko jelas lebih sulit dibanding dengan Teori Balok EulerBernoulli. Sebaiknya Teori Balok Timoshenko tidak dilakukan jika dampak yang ditimbulkan tidak memberikan pengaruh yang besar. Oleh sebab itu, ada baiknya dilakukan penelitian untuk membahas kondisi seperti apa yang membuat Teori Balok Timoshenko perlu dilakukan untuk analisis dinamik.

\section{Frekuensi Alami pada Balok Euler-Bernoulli}

Untuk bisa menghitung frekuensi ini, perlu dicari suatu nilai $\beta$ sesuai perletakan balok yang dianalisis. Dengan L adalah panjang balok, nilai $\beta$ merupakan nilai yang memenuhi persamaan sesuai tabel 2.1 di bawah ini.

Tabel 1. Persamaan untuk Menghitung Nilai $\beta$

\begin{tabular}{cc}
\hline Perletakan & Persamaan \\
\hline Jepit-Bebas & $\cosh (\beta L) \cos (\beta L)+1=0$ \\
\hline Jepit-Jepit & $\cosh (\beta L) \cos (\beta L)-1=0$ \\
\hline Jepit-Sendi & $\cos (\beta L)=0$ \\
\hline Sendi-Sendi & $\sin (\beta L)=0$ \\
\hline
\end{tabular}

Jika nilai $\beta$ sudah didapat, maka frekuensi balok Euler-Bernoulli bisa dihitung dengan rumus:

$$
f_{n}=\frac{\beta^{2}}{2 \pi} \sqrt{\frac{E I}{\rho A}}
$$

Dengan $f_{n}=$ frekueansi alami balok Euler-Bernoulli, $\beta=$ nilai yang didapat dari Tabel 2.1, $E=$ modulus elastisitas bahan, $\mathrm{I}=$ momen inersia penampang balok, $\rho=$ masa jenis bahan dan $\mathrm{A}=$ Luas penampang balok.

\section{Mode Shape pada Balok Euler-Bernoulli}

Fungsi dari bentuk pola getaran mode shape bisa ditentukan pada Tabel 2.2 di bawah ini sesuai perletakan balok yang dianalisis.

Tabel 2. Fungsi Mode Shape sesuai Jenis Perletakan

\begin{tabular}{cc}
\hline Perletakan & Persamaan \\
\hline Jepit-Bebas & $Y=(\cosh (\beta x)-\cos (\beta x))-\left(\frac{\cosh (\beta L)+\cos (\beta L)}{\sinh (\beta L)+\sin (\beta L)}\right)(\sinh (\beta x)-\sin (\beta x))$ \\
\hline Jepit-Jepit & $Y=(\sinh (\beta x)-\sin (\beta x))-\left(\frac{\sinh (\beta L)+\sin (\beta L)}{\cosh (\beta L)+\cos (\beta L)}\right)(\cosh (\beta x)-\cos (\beta x))$ \\
\hline Jepit-Sendi & $Y=(\cosh (\beta x)-\cos (\beta x))-\left(\frac{\cosh (\beta L)+\cos (\beta L)}{\sinh (\beta L)-\sin (\beta L)}\right)(\sinh (\beta x)-\sin (\beta x))$ \\
\hline Sendi-Sendi & $Y=\sin (\beta x)$ \\
\hline
\end{tabular}

\section{Frekuensi Alami pada Balok Timoshenko}

Untuk bisa menghitung frekuensi ini, perlu dicari beberapa nilai terlebih dahulu yaitu d, e, $\Delta, \lambda_{1}$ dan $\lambda_{2}$ dengan menggunakan rumus-rumus dibawah ini.

$$
\begin{gathered}
d=\frac{\omega^{2} \rho\left(1+\frac{E}{\kappa G}\right)}{E} \\
e=\frac{\omega^{2}\left(\omega^{2} \rho^{2} \frac{1}{\kappa G}-\rho A\right)}{E I}
\end{gathered}
$$




$$
\begin{gathered}
\Delta=d^{2}-4 e \\
\lambda_{1}^{2}=\frac{1}{2}(-d+\sqrt{\Delta}) \\
\lambda_{2}^{2}=\frac{1}{2}(d+\sqrt{\Delta})
\end{gathered}
$$

Dengan $\omega=$ kecepatan sudut, $\mathrm{K}=$ faktor modifokasi bentuk dan $\mathrm{G}=$ modulus geser bahan.

Semua parameter yang dibutuhkan bisa ditentukan berdasarkan bentuk penampang struktur dan bahan yang digunakan kecuali kecepatan sudut. Kecepatan sudut adalah parameter yang dicari karena jika kecepatan sudut sudah diketahui, frekuensi alami bisa dengan mudah dihitung. Karena kecepatan sudut belum bisa ditentukan dari awal maka d, e, $\Delta, \lambda_{1}$ dan $\lambda_{2}$ merupakan bentuk persamaan polinomial dengan variabel $\omega$. Kemudian yang selanjutnya perlu dilakukan adalah pencari nilai $\omega$ yang memenuhi persamaan matriks dibawah ini.

$$
\left|\begin{array}{cc}
\sin \left(\lambda_{1} L\right) & \sin \left(\lambda_{2} L\right) \\
\lambda_{1}^{2} \sin \left(\lambda_{1} L\right) & -\lambda_{2}^{2} \sin \left(\lambda_{2} L\right)
\end{array}\right|=0
$$

Persamaan ini hanya bisa digunakan untuk mencari $\omega$ dari balok dengan perletakan sendi-rol. Dengan memasukan panjang balok yaitu L dan parameter lainnya, $\omega$ dapat ditentukan.

Frekuensi alami dan kecepatan sudut merupakan parameter yang identik. Perbedaannya hanya terletak pada satuannya saja. Satuan dari kecepatan sudut adalah rad/s sedangkan frekuensi alami adalah Hz yaitu 1/s. Sehingga untuk menentukan frekuensi alami dari kecepatan sudut hanya perlu membagi $\omega$ dengan $2 \pi$ rad yaitu sudut dari satu lingkaran penuh. Dibawah ini merupakan rumus dari frekuensi alami.

$$
f_{n}=\frac{\omega}{2 \pi}
$$

\section{Mode Shape pada Balok Timoshenko}

Persamaan fungsi dari bentuk pola getaran mode shape bisa ditentukan sesuai perletakan balok yang dianalisis. Untuk balok dengan perletakan sendi-rol, fungsi yang bekerja adalah fungsi di bawah ini.

$$
X(x)=\sin \left(\lambda_{1} x\right)
$$

\section{METODE ELEMEN HINGGA}

Metode elemen hingga merupakan metode pendekatan yang dipelajari untuk bisa digunakan di berbagai analisis yang sulit diselesaikan jika dikerjakan secara eksak. Beberapa analisis seperti analisis struktur merupakan analisis yang jika dikerjakan dengan metode eksak akan sangat sulit karena langkah-langkah pengerjaan analisisnya berbeda-beda sesuai dengan bentuk struktur, perletakan-perletakan yang ada, beban-beban yang bekerja, dan jenis material yang digunakan. Terlebih sulit lagi jika beban yang bekerja merupakan beban dinamik yang besarnya bergantung pada waktu, tidak seperti beban statik yang besarnya akan selalu sama.

Cara kerja metode elemen hingga adalah dengan memecah (mendiskritisasi) atau dalam bahasa inggris disebut meshing merupakan suatu proses pemodelan sebuah struktur atau objek dengan membaginya ke dalam elemenelemen kecil (elemen hingga) yang terhubung oleh dua atau lebih titik (nodes) dan digunakan sebagai batas dari struktur atau objek tersebut. Dalam metode elemen hingga, tidak dilakukan pemecahan permasalahan elemen struktur secara keseluruhan dalam satu kali operasi, melainkan membuat formulasi persamaan untuk masing-masing elemen hingga, kemudian menggabungkannya untuk memperoleh solusi untuk elemen strukturnya. Secara singkat, solusi dari permasalahan struktur yang dimaksud adalah menghitung besarnya perpindahan dan tegangan yang dialami struktur akibat adanya beban yang bekerja (Logan, 2011).

Jika struktur yang dianalisis terlalu rumit, walaupun langkah-langkah dari metode elemen hingga sederhana, tetap akan menjadi sulit karena terlalu banyak yang harus dikerjakan sehingga kemungkinan terjadi kesalahan menjadi sangat besar. Oleh sebab itu, lebih baik dikerjakan dengan program pada komputer.

Karena metode elemen hingga ini merupakan metode pendekatan, hasil yang didapat bukanlah hasil yang tepat. Namun, kita dapat memperkecil kesalahan yang terjadi dengan memperbanyak jumlah dari titik dan elemen dalam 
perhitungan. Semakin banyak elemen dan titik yang dianalisis, kesalahan yang terjadi akan semakin kecil. Banyaknya elemen ini disesuaikan dengan kebutuhan dari struktur yang ingin dibangun.

\section{Langkah-Langkah Pemodelan dan Analisa Struktur Balok dengan Elemen Batang dengan Program Berbasis Elemen Hingga}

a. $\quad$ Material Property Data

Pada menu Material Property Data, masukan data-data material yang digunakan seperti modulus elastisitas, masa jenis, dan rasio poisson.

b. Rectangular Section

Pada menu Rectangular Section, tentukan dimensi penampang balok dan pilih material sesuai jenis yang sudah ditentukan.

c. Beam

Setelah bahan atau material dan bentuk penampang sudah ditentukan sesuai struktur yang akan dianalisis, masukan bentuk struktur yaitu balok sesuai diskritisasi. Untuk mendapatkan hasil yang akurat, diperlukan banyak elemen. Pada analisis ini digunakan 50 elemen batang. Karena panjang bentang balok 10 meter, maka panjang elemen adalah 10 meter dibagi 50 yaitu 0.2 meter.

d. Assign Joint Restraints

Setelah balok sudah terbentuk, tentukan perletakan sesuai struktur yang ingin dianalisis yaitu sendi di ujung kiri dan kanan balok.

e. Analysis Options

Analisis yang akan dikerjakan hanya bekerja di arah $\mathrm{X}$ dan $\mathrm{Z}$ yaitu panjang balok dan tinggi balok. Maka harus ditentukan derajad kebebasan yang datar agar tidak mengeluarkan hasil diluar arah X dan Z.

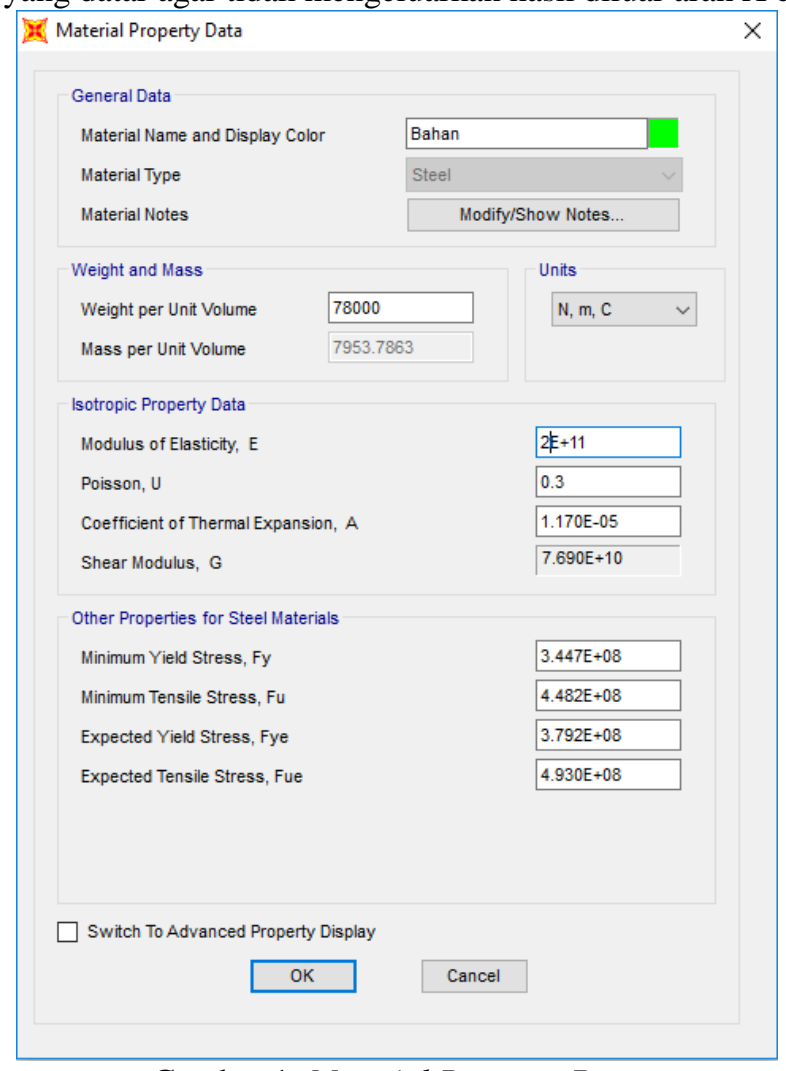

Gambar 1. Material Property Data 


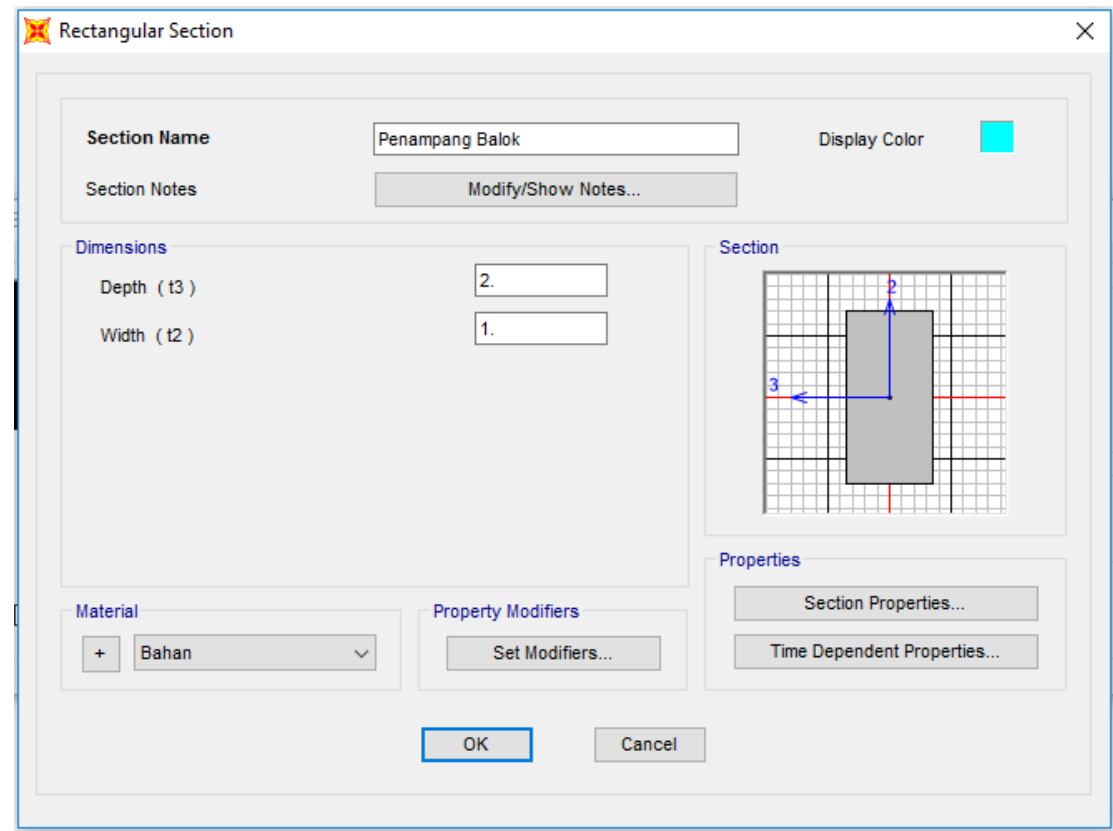

Gambar 2. Rectangular Section

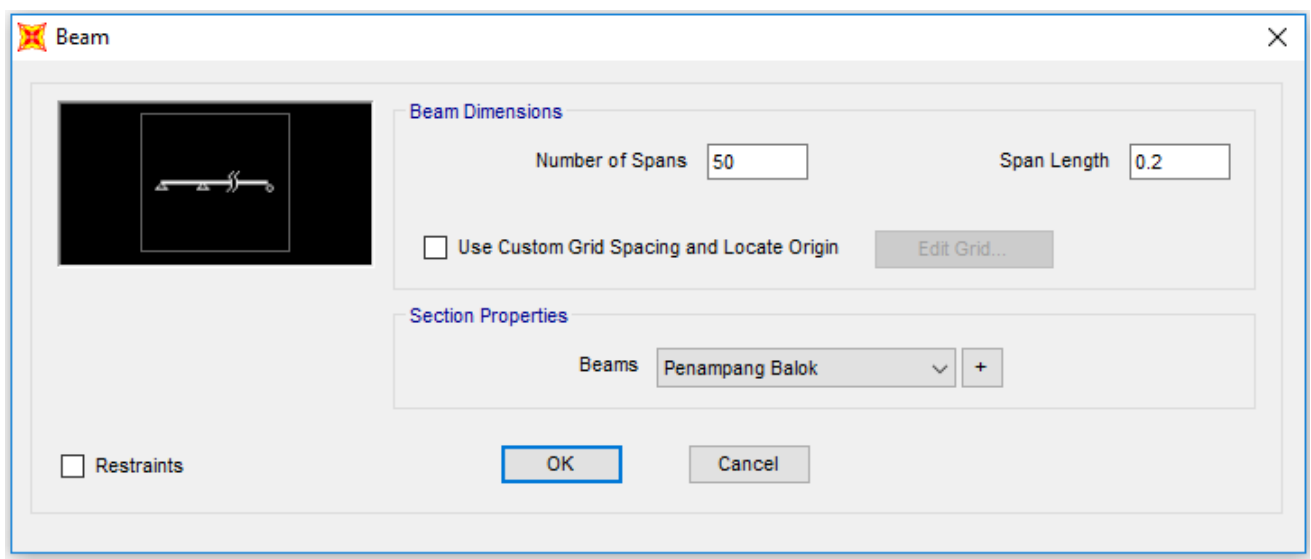

\section{Gambar 3. Beam}

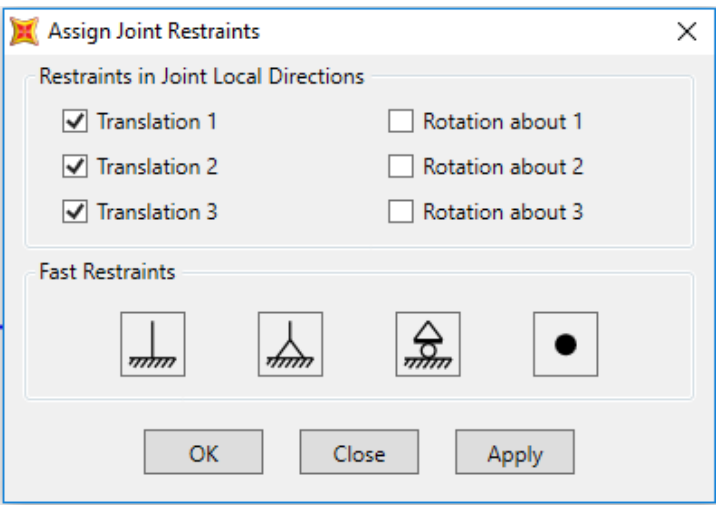

Gambar 4. Assign Joint Restraints

Gambar 5. Model Balok dengan Elemen Batang dengan Perletakan 


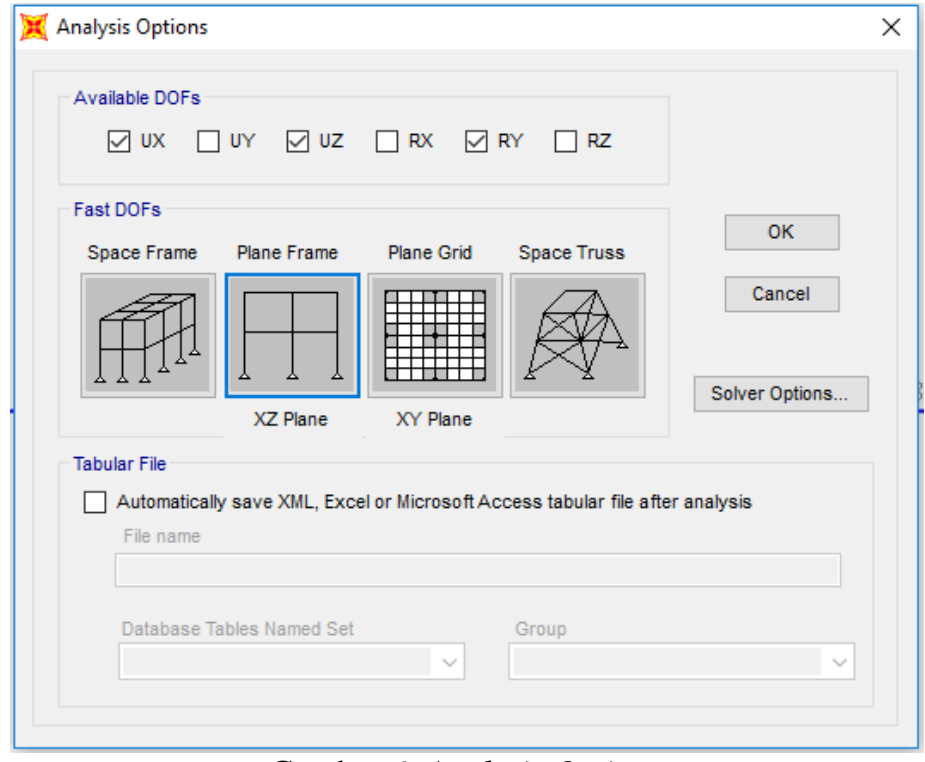

Gambar 6. Analysis Options

\section{Langkah-Langkah Pemodelan dan Analisa Struktur Balok dengan Elemen Plane Stress dengan Program Berbasis Elemen Hingga}

a. $\quad$ Material Property Data

Pada menu Material Property Data, masukan data-data material yang digunakan seperti modulus elastisitas, masa jenis, dan rasio poisson.

b. $\quad$ Plane Section Data

Pada menu ini bisa ditentukan jenis elemen dua dimensi, jenis material, dan dimensi elemen. Jenis elemen yang dipilih adalah plane stress yaitu elemen yang menahan tegangan dua arah yaitu arah X dan Z. Jenis material dipilih sesuai dengan elemen yang sudah diatur di menu material property data. Dimensi elemen yang diatur di menu ini adalah tebal elemen sedangkan dimensi yang lain bisa disesuaikan dengan kebutuhan pemodelan.

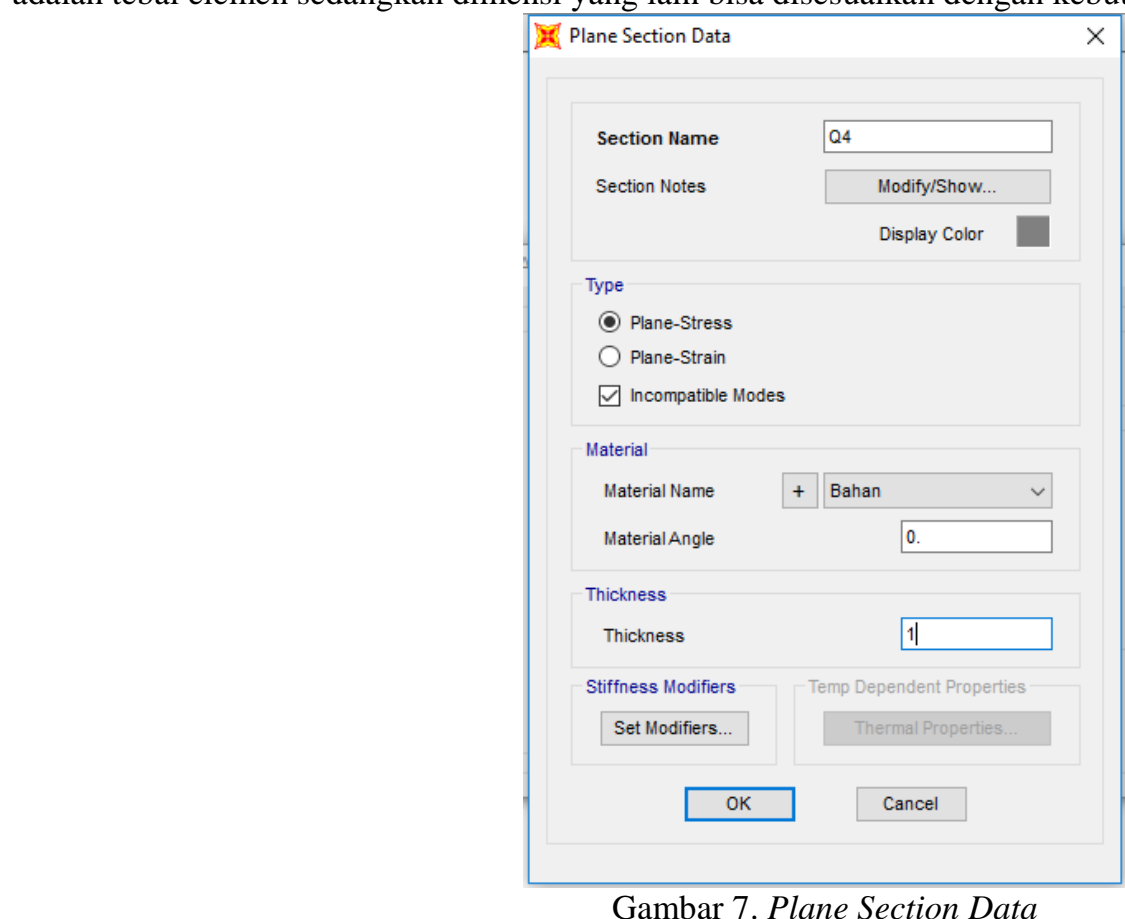

\section{c. $\quad$ Shear Wall}

Gambar 7. Plane Section Data

Setelah jenis elemen dan jenis material sudah diatur sesuai kebutuhan analisis, tentukan bentuk balok sesuai diskritisasi yang dibutuhkan. Agar analisis mengeluarkan hasil yang akurat, elemen yang dibentuk tidak boleh sedikit. Untuk analisis ini, semua elemen berukuran 0.1 meter kali 0.1 meter. Karena panjang balok adalah 10 meter, 
jumlah elemen pada arah $\mathrm{X}$ adalah 10 bagi 0.1 yaitu 100. Sedangkan jumlah elemen pada arah Z ditentukan dari tinggi balok bagi 0.1 meter.

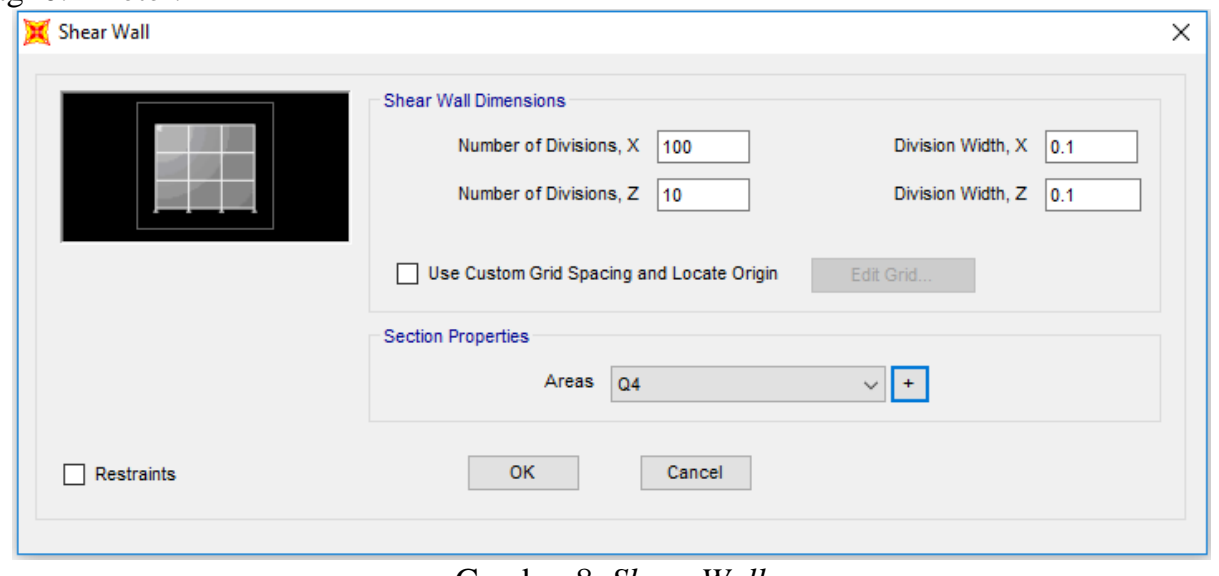

d. Assign Joint Restraints

Gambar 8. Shear Wall

Setelah balok sudah terbentuk, tentukan perletakan sesuai struktur yang ingin dianalisis yaitu sendi di ujung kiri dan kanan balok. Untuk model dua dimensi, boundary condition yang sesuai untuk perletakan sendi adalah displacement arah vertikat di seluruh bagian penampang ditahan sedangkan di bagian tengah penampang displacement arah vertikal dan horizontal ditahan seperti gambar di bawah.

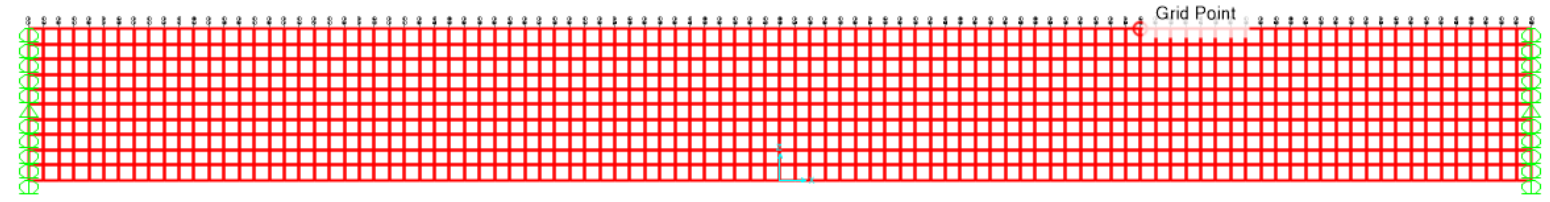

Gambar 9. Model Balok dengan Elemen Plane Sress dengan Perletakan

\section{e. Analysis Options}

Analisis yang akan dikerjakan hanya bekerja di arah X dan Z yaitu panjang balok dan tinggi balok. Maka harus ditentukan derajad kebebasan yang datar agar tidak mengeluarkan hasil diluar arah X dan Z.

\section{ANALISIS DAN PEMBAHASAN}

Balok yang dianalisis memiliki panjang bentang 10 meter dan lebar penampang 1 meter dengan perletakan sendi di ujung kiri dan kanan. Analisis ini akan dilakukan dengan dua metode yaitu metode teoritis atau dan metode elemen hingga yang dikerjakan pada program komputer. Metode teoritis yang dipakai adalah Teori Balok Euler-Bernoulli dan Teori Balok Timoshenko. Jenis elemen yang digunakan untuk analisis dengan metode elemen hingga adalah elemen batang dan elemen plane stress bujur sangkar(Q4).

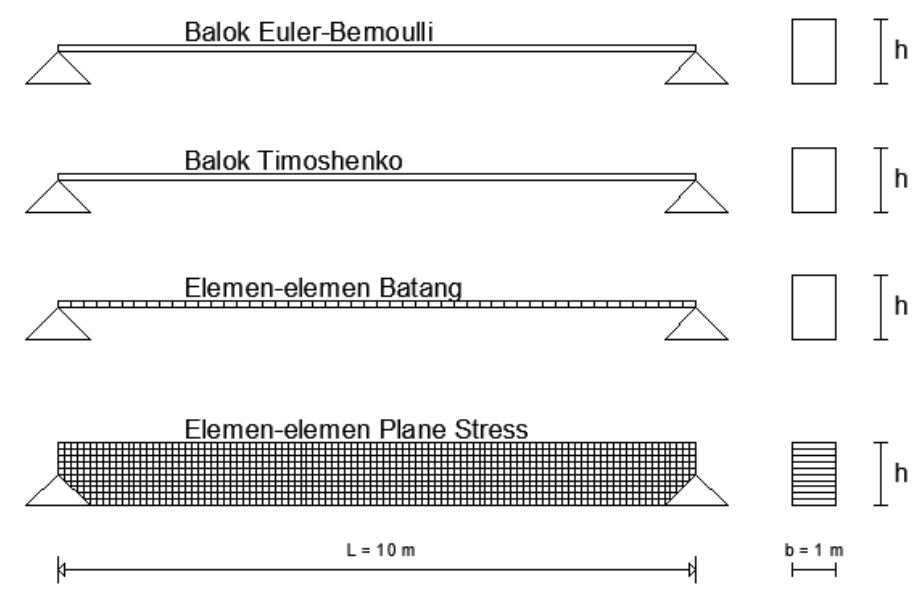

Gambar 10. Pemodelan Balok 
Analisis dilakukan untuk menghitung frekuensi alami balok dan menampilkan mode shape dari mode 1, 2 , dan 3. Tinggi dari penampang balok bervariasi sesuai dengan kebutuhan untuk menganalisis pengaruh rasio L/h (panjang bentang banding tinggi penampang) terhadap frekuensi alami balok dan mode shape dari mode 1, 2, dan 3.

Setelah semua metode dikerjakan, didapatlah frekuensi alami dan mode shape dari balok dengan berbagai macam fariasi L/h (perbandingan panjang bentang dengan tinggi penampang). Dari data-data tersebut, dibuatlah grafikgrafik untuk membandingkan hasil dari masing-masing metode.

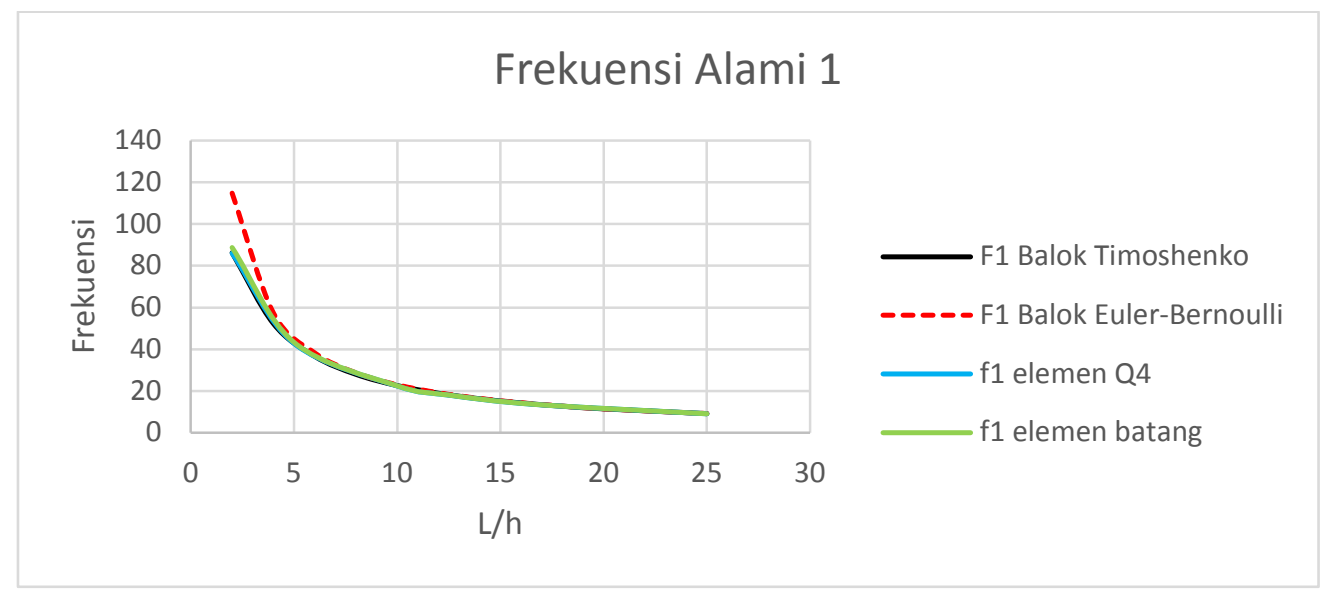

Gambar 11. Frekuensi Alami pada Mode 1

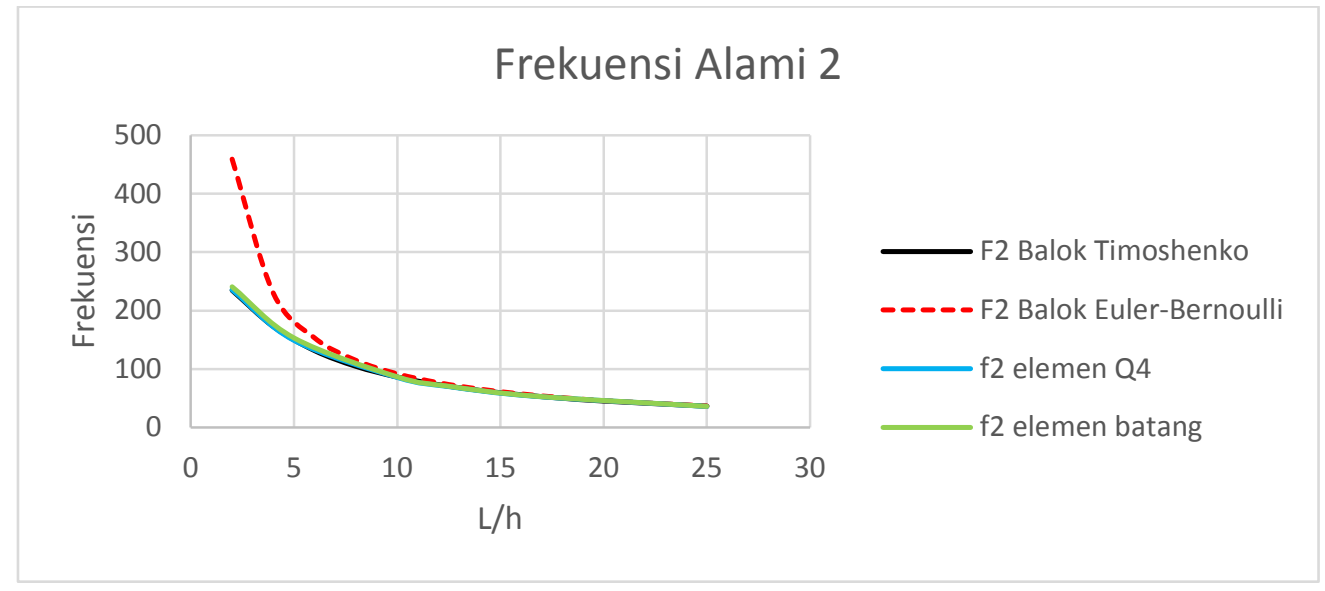

Gambar 12. Frekuensi Alami pada Mode 2

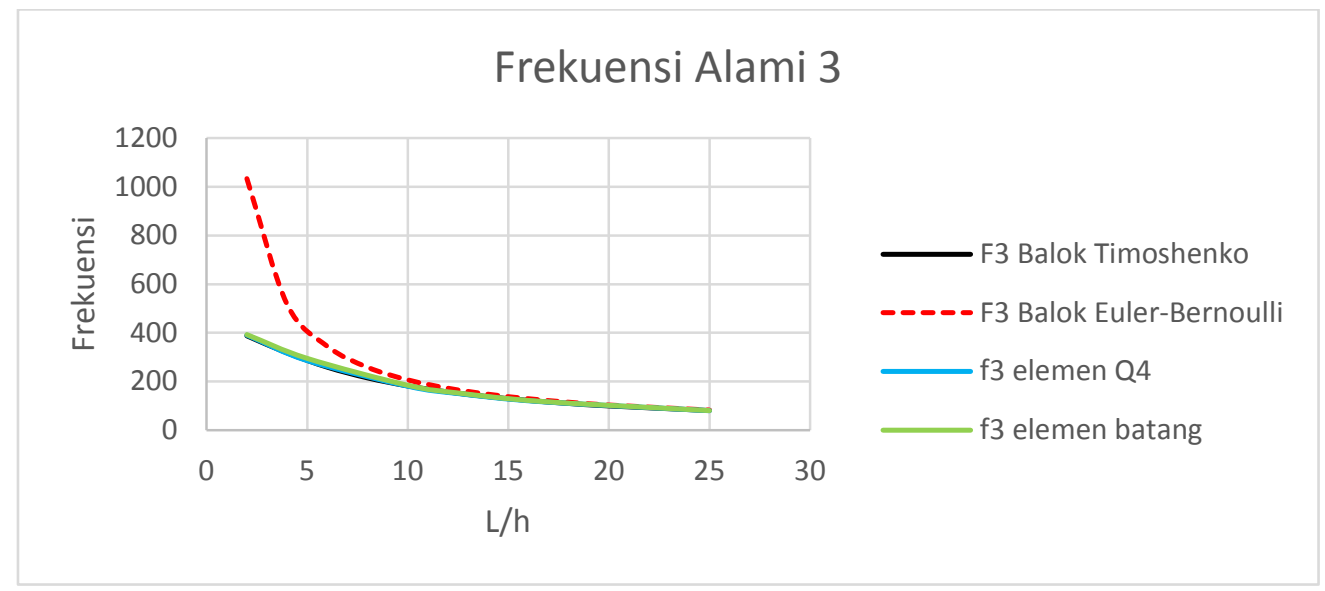

Gambar 13. Frekuensi Alami pada Mode 3 


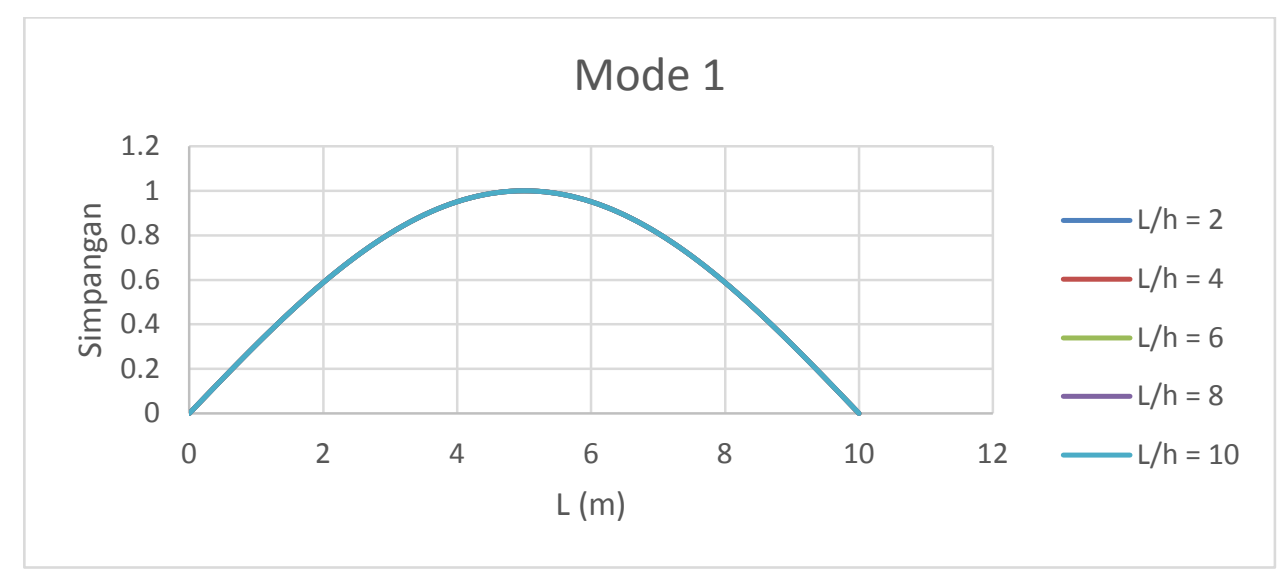

Gambar 14. Mode 1 Balok Sendi-Sendi

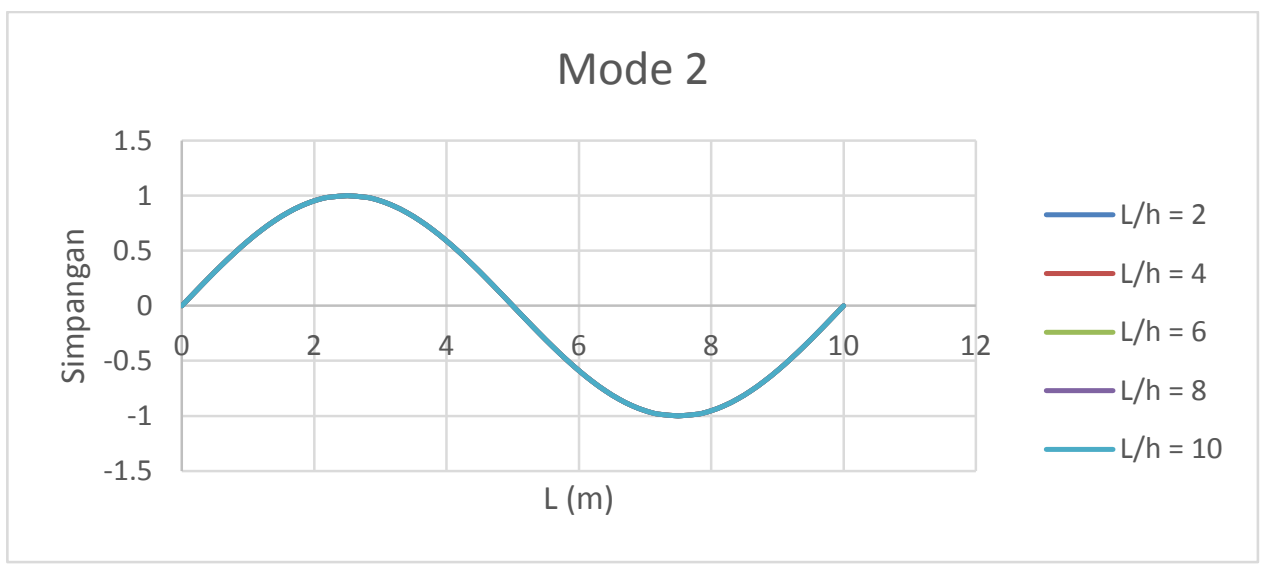

Gambar 15. Mode 2 Balok Sendi-Sendi

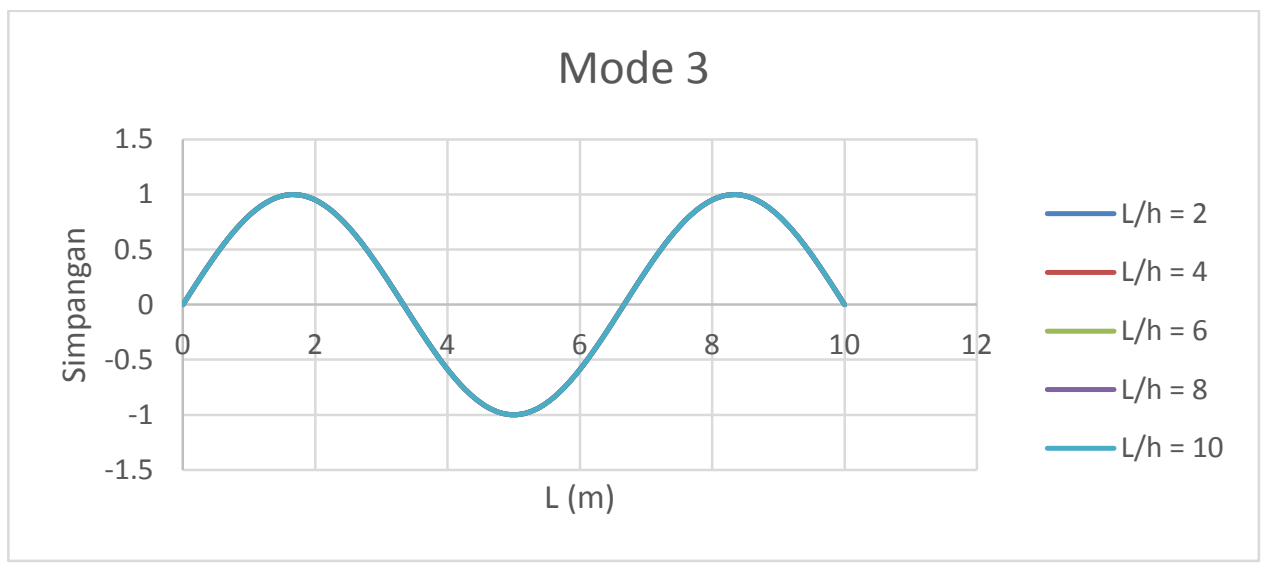

Gambar 16. Mode 3 Balok Sendi-Sendi

\section{KESIMPULAN}

Berdasarkan grafik-grafik yang dihasilkan dari studi kasus, dapat ditarik beberapa kesimpulan sebagai berikut:

1. Analisis frekuensi alami pada mode 1 sebaiknya menggunakan Teori Balok Timoshenko jika L/h (rasio perbandingan panjang balok dengan tinggi penampang) lebih kecil dari 4, untuk frekuensi alami pada mode 2 sebaiknya menggunakan Teori Balok Timoshenko jika L/h lebih kecil dari 8, dan untuk frekuensi alami pada mode 3 sebaiknya menggunakan Teori Balok Timoshenko jika L/h lebih kecil dari 12.

2. Analisis balok dengan elemen batang dan elemen plane stress pada program berbasis elemen hingga menghasilkan frekuensi alami balok sesuai dengan Teori Balok Timoshenko. 
3. Mode shape balok yang dianalisis menggunakan elemen batang, elemen plane stress, Teori Balok EulerBernoulli, dan Teori Balok Timoshenko menghasilkan bentuk yang serupa.

\section{Saran}

Berdasarkan proses pengerjaan studi ini ditemukan beberapa kesulitan, maka dari itu penulis memberikan saran untuk studi selanjutnya:

1. Untuk hasil yang lebih akurat perlu dilakukan uji eksperimen pada penelitian selanjutnya.

2. Untuk penelitian selanjutnya dapat diganti tipe perletakan dengan tipe kondisi batas lainnya.

3. Dapat dicoba permodelan dengan material lain seperti beton dengan memperhitungkan tulangan dan retakan.

\section{DAFTAR PUSTAKA}

Carrera, E., G. Giunta, dan M. Petrolo. (2011). Beam Structure Classical and Advanced Theories, John Wiley \& Sons, Ltd, United Kingdom.

Chopra, Anil K. (2007). Dynamics of Structures Theory and Applications to Earthquake Engineering, Pearson Education, Inc., Upper Saddle River, New Jersey.

Logan, Daryl L. (2012). A First Course in the Finite Element Method, Cengange Learning, United States.

Majkut, Leszek. (2009). "Free and Forced Vibrations of Timoshenko Beams Described by Singgle Difference Equation.” Journal of Theoretical and Applied Mechanics, Vol. 47, No. 1, hal. 193-210.

Mukherjee, A., Agnivo G. (2010). “Determination of Natural Frequency of Euler's Beams Using Analytical and Finite Element Method.” Department of Mechanical Engineering.

Sacharissa, Z., Leo S. T. (2018). “Analisis Perbandingan Displacement pada Balok Euler-Bernoulli dan Timoshenko dengan Metode Finite Element.” Skripsi Teknik Sipil Universitas Tarumanagara. 